\title{
Histopathological Features of Ayu Plecoglossus altivelis Experimentally Infected with Pseudomonas plecoglossicida
}

\author{
Tatsuya Kobayashi* and Makoto Imai \\ Kyowa Yakuhin Co., Ltd., Wakayama, 641-0036, Japan
}

(Received November 21, 2005)

\begin{abstract}
Histopathology of experimentally infected ayu Plecoglossus altivelis with bacterial hemorrhagic ascites (BHA) was studied in order to determine its histopathological features. Fish (2.3 $\mathrm{g}$ in average weight, $\mathrm{n}=108$ ) were infected with Pseudomonas plecoglossicida by immersion (IM) (ca. $10^{7} \mathrm{CFU} / \mathrm{mL}$ ), intraperitoneal injection (IPI) (ca. $10^{4}$ and $10^{7} \mathrm{CFU} /$ fish) and intramuscular injection (IMI) (ca. $10^{4}$ and $10^{7} \mathrm{CFU} /$ fish). The cumulative mortalities ranged from 92.9 to $100 \%$. In the IM challenge groups, necrotic lesions accompanied by edema, fibrin deposition and hemorrhage were observed in the splenic and hematopoietic tissues. In some fish, the liver had necrotic lesions and microabscesses. In both the IPI and IMI challenge groups, lesions of the spleen and kidney were similar to those of the IM challenge groups. In addition, necrotic lesions and hemorrhage in the abdominal adipose tissue and pancreas were often observed in the IPI challenge groups. In the IMI challenge groups, the infected fish had definite lesions of the musculature at the injected site. The results revealed that the lesion formation in the spleen and kidney was the main pathological changes of BHA in ayu.
\end{abstract}

Keywords: Pseudomonas plecoglossicida, bacterial hemorrhagic ascites, Plecoglossus altivelis, ayu, experimental infection, histopathology

Bacterial hemorrhagic ascites (BHA) is a serious disease of ayu Plecoglossus altivelis that is responsible for significant losses to the ayu farming industry in Japan. Typical gross pathological signs are pale body coloration, distended abdomen resulting from ascites, pale gill coloration, bloody ascitic fluid in the peritoneal cavity, congested liver, splenomegaly, kidney swelling and occasional hemorrhage in the adipose tissue (Wakabayashi et al., 1996, Kobayashi et al., 2004). The causative agent has been identified as Pseudomonas plecoglossicida (Nishimori et al., 2000). No licensed chemotherapeutics such as antibiotics are effective against BHA. However, success in controlling BHA has been achieved experimentally with vaccination and specific bacteriophages (Sukenda and Wakabayashi, 1999; Ninomiya and Yamamoto, 2001; Park and Nakai, 2003).

In the previous studies, ayu were successfully infected with $P$. plecoglossicida by various methods, that is, immersion (Sukenda and Wakabayashi, 2000), intra-

\footnotetext{
* Corresponding author

E-mail: f-kobayashi@k9.dion.ne.jp
}

peritoneal injection (Wakabayashi et al., 1996), intramuscular injection and oral administration (Park and Nakai, 2003). However, the pathological effects of these experimental infections were unclear because of a lack of histopathological examinations. We have previously described the histopathology of naturally diseased fish of BHA (Kobayashi et al., 2004). In the present study, we describe histopathological features of ayu experimentally infected by immersion, intraperitoneal injection and intramuscular injection.

\section{Materials and Methods}

Fish and bacterial strains

Ayu weighing about $2.3 \mathrm{~g}$ were obtained from a farm in Wakayama prefecture, Japan. These fish had never experienced BHA. Fish were maintained in a tank with dechlorinated tap water at $18^{\circ} \mathrm{C}$ and fed daily, but not fed for $24 \mathrm{~h}$ prior to the experiments.

The $P$. plecoglossicida strain (WKPP-03) used in this study was isolated from a diseased ayu at Wakayama prefecture in 2003 (Kobayashi et al., 2004). The WKPP-03 was a non-motile strain. The strain was 
Table 1. Experimental infection with Pseudomonas plecoglossicida in the ayu Plecoglossus altivelis

\begin{tabular}{|c|c|c|c|c|c|c|c|c|}
\hline \multirow[b]{2}{*}{ Infection group } & \multicolumn{3}{|c|}{ High dose group } & \multicolumn{3}{|c|}{ Low dose group } & \multicolumn{2}{|c|}{ Control } \\
\hline & Dose & $\begin{array}{c}\text { No. of fish } \\
\text { dead / examined }\end{array}$ & $\begin{array}{c}\text { Mortality } \\
(\%)\end{array}$ & Dose & $\begin{array}{c}\text { No. of fish } \\
\text { dead / examined }\end{array}$ & $\begin{array}{l}\text { Mortality } \\
(\%)\end{array}$ & $\begin{array}{c}\text { No. of fish } \\
\text { dead / examined }\end{array}$ & $\begin{array}{c}\text { Mortality } \\
(\%)\end{array}$ \\
\hline Immersion (IM) & $2.1 \times 10^{7 * 1}$ & $15 / 16$ & 93.8 & $9 \times 10^{6 * 1}$ & $14 / 15$ & 93.3 & $0 / 15$ & 0 \\
\hline Intraperitoneal injection (IPI) & $6.5 \times 10^{7 * 2}$ & $16 / 16$ & 100 & $6.5 \times 10^{4 * 2}$ & $13 / 14$ & 92.9 & $1 / 13^{* 3}$ & 7.7 \\
\hline Intramuscular injection (IMI) & $2.3 \times 10^{7 * 2}$ & $9 / 9$ & 100 & $2.3 \times 10^{4 * 2}$ & $10 / 10$ & 100 & $0 / 10$ & 0 \\
\hline
\end{tabular}

pre-cultured on modified Trypto-Soya (MTS) agar (Kobayashi et al., 2004) at $25^{\circ} \mathrm{C}$ for 2 days.

\section{Experimental infection}

Fish were experimentally infected by three methods: immersion (IM), intraperitoneal injection (IPI) and intramuscular injection (IMI) with high and low doses of the bacteria. The doses and total number of fish used in each experimental group are shown in Table 1. In the IM challenge, bacteria were cultured in brain heart infusion (BHI) broth (Eiken Chemical Co., Ltd.) at $25^{\circ} \mathrm{C}$ for 2 days, and then $100 \mathrm{~mL}$ of $\mathrm{BHI}$ broth with bacteria was diluted 1: 10 with dechlorinated tap water. The IM challenge was performed by immersing fish in the diluted $\mathrm{BHI}$ with bacteria at $18^{\circ} \mathrm{C}$ for $15 \mathrm{~min}$. Control fish were immersed for $15 \mathrm{~min}$ in sterile BHI broth diluted 1: 10 with dechlorinated tap water.

In the IPI and IMI challenge groups, bacteria cultured on MTS agar plate at $25^{\circ} \mathrm{C}$ for 2 days were suspended in sterile physiological saline. In the IPI challenge, ayu were injected intraperitoneally with $0.05 \mathrm{~mL} /$ fish of the bacterial suspension. In the IMI challenge, ayu were injected intramuscularly below a dorsal fin with $0.05 \mathrm{~mL} / \mathrm{fish}$ of the bacterial suspension. Control groups received injections of an equivalent volume of sterile physiological saline.

After the experimental inoculation, fish were held in aerated aquaria at $18^{\circ} \mathrm{C}$ and clinical signs and mortality were checked daily. Moribund and dead fish were taken out as soon as they appeared. All of the fish were necropsied, and we attempted to isolate bacteria from the trunk kidney with MTS agar plates. The bacterial isolates were examined with a slide agglutination test using a rabbit antiserum against $P$. plecoglossicida FPC941.

\section{Histopathological examination}

The brain, gill, heart, liver, spleen, trunk kidney, pancreas, digestive tracts, and trunk musculature of all of the experimental fish were fixed in phosphate-buffered $10 \%$ formalin solution, embedded in paraffin and sectioned at $4 \mu \mathrm{m}$. These sections were stained with hematoxylin and eosin (H\&E), Giemsa, periodic acidSchiff reaction or Azan.

\section{Results}

Cumulative mortalities, gross pathological features and bacterial reisolation

Cumulative mortalities of the three experimental groups, IM, IPI and IMI challenge groups, are shown in Figs. 1-3, respectively. In the IM challenge, the fish of high $\left(2.1 \times 10^{7} \mathrm{CFU} / \mathrm{mL}\right)$ and low $\left(9 \times 10^{6} \mathrm{CFU} / \mathrm{mL}\right)$ dose groups began to become moribund and/or die at 3 and 4 days after inoculation, and cumulative mortalities reached $93.8 \%$ and $93.3 \%$, respectively. In the IPI challenge, the fish of high $\left(6.5 \times 10^{7} \mathrm{CFU} /\right.$ fish $)$ and low $\left(6.5 \times 10^{4} \mathrm{CFU} / \mathrm{fish}\right)$ dose groups began to become moribund and/or die at 1 and 3 days after inoculation and cumulative mortalities reached $100 \%$ and $92.9 \%$, respectively. In the IMI challenge, the fish of high $(2.3 \times$ $10^{7} \mathrm{CFU} /$ fish) and low (2.3 $\times 10^{4} \mathrm{CFU} /$ fish $)$ dose groups began to become moribund and/or die at 1 and 4 days after inoculation and cumulative mortalities reached both $100 \%$.

Most of the experimentally infected fish showed pale body coloration, pale gill coloration, liver congestion, splenomegaly and kidney swelling. Of the 80 tested fish, a total of 38 had bloody ascites in the peritoneal cavities (IM; high dose group: 9 of 16 tested fish, low dose group: 7 of 15 tested fish. IPI; high dose group: 6 of 16 tested fish, low dose group: 7 of 14 tested fish. IMI; high dose group: 4 of 9 tested fish, low dose group: 5 of 10 tested fish). In addition, infected fish of the IPI challenge often had hemorrhage of the abdominal adipose tissue. In the IMI challenge groups, all of the experimentally infected fish possessed cutaneous erosive lesions with hemorrhage around injection site at 1-2 days after inoculation.

The inoculated bacteria were successfully isolated from the kidneys of all of the infected fish. In contrast, neither lesions nor bacteria were detected in the survivors of each challenge group and in the fish of control groups including one dead fish in IPI control.

\section{Histopathological changes}

All of moribund and dead fish in the IM, IPI and IMI challenge groups had distinct lesions in the spleen and kidney. 


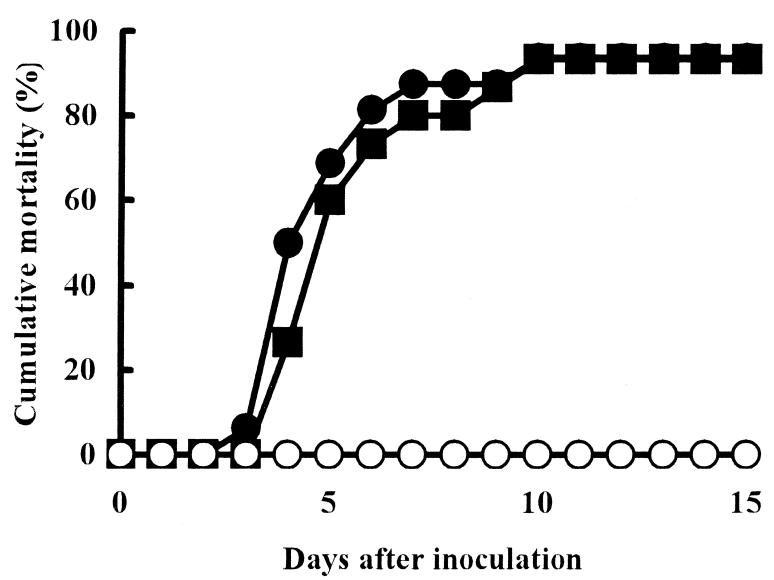

Fig. 1. Cumulative mortalities among ayu after immersion infection with $P$. plecoglossicida. 0 : challenged with $2.1 \times 10^{7} \mathrm{CFU} / \mathrm{mL}, \boldsymbol{\square}$ : challenged with $9 \times 10^{6} \mathrm{CFU} /$ $\mathrm{mL}, \bigcirc$ : control

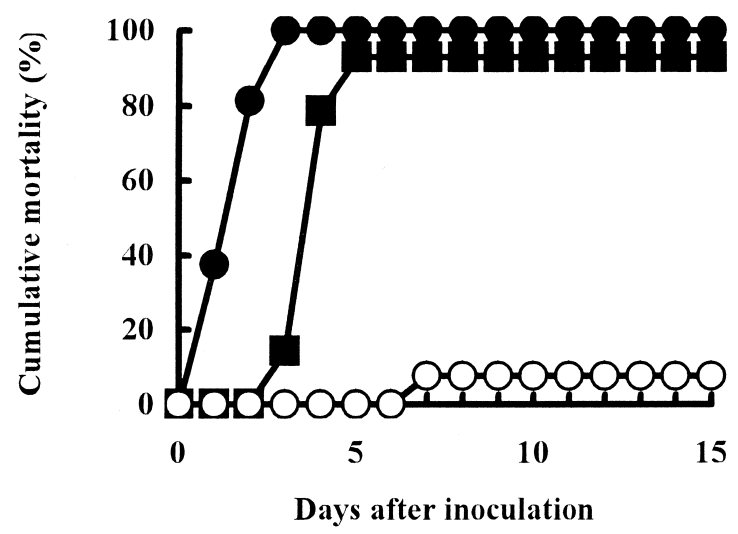

Fig. 2. Cumulative mortalities among ayu after intraperitoneal injection with $P$. plecoglossicida. $\quad$ : challenged with $6.5 \times 10^{7} \mathrm{CFU} / \mathrm{fish}, \mathbf{\square}$ : challenged with $6.5 \times 10^{4} \mathrm{CFU} /$ fish, $\bigcirc$ : control

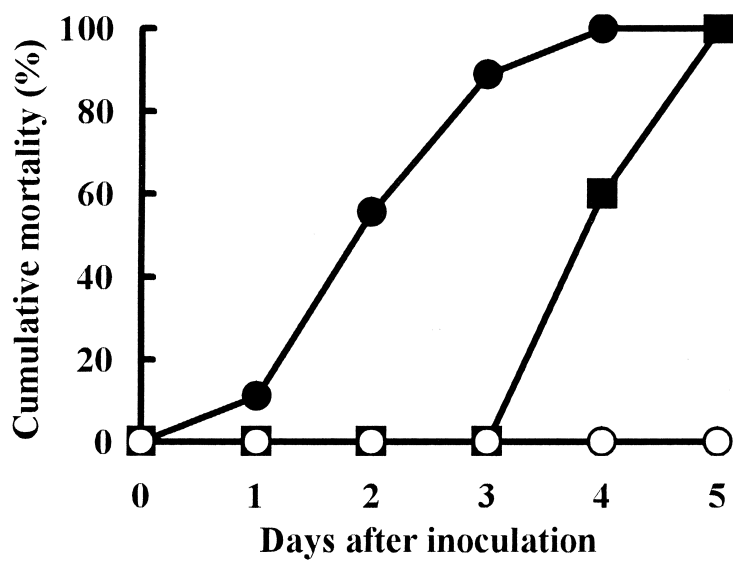

Fig. 3. Cumulative mortalities among ayu after intramuscular injection with $P$. plecoglossicida. 0 : challenged with $2.3 \times 10^{7} \mathrm{CFU} / \mathrm{fish}, \mathbf{\square}$ : challenged with $2.3 \times 10^{4} \mathrm{CFU} /$ fish, $\bigcirc$ : control
In the IM challenge groups, splenic tissues were invaded with bacteria and were extensively necrotized and hemorrhaged (Fig. 4A). Necrotic cells showed karyorrhexis and karyopyknosis. Necrotic lesions were often accompanied by edema and fibrin deposition. The sheathed arteries and the blood vessels of the splenic pulps were also necrotized and accompanied by fibrinoid degeneration (Fig. 4B). Fibrinous inflammation was usually observed in diseased fish that had ascites fluid.

In the kidney, the hematopoietic tissue had extensive necrotic lesions with bacteria (Fig. 4C). The lesions were accompanied by edema, fibrin deposition and dilation of sinusoids, while the renal tubular epithelia were separated from the basement membranes. Necrotic cells showed karyorrhexis, karyopyknosis and hyperchromatosis of the nuclear membrane. Renal tubular epithelial cells often contained hyaline droplets or displayed cloudy swelling, whereas no bacteria were present in the lesions of the renal tubular epithelia. Lesions of the spleen and kidney were observed in all of the infected fish. In some fish that were moribund at 6 10 days after inoculation, microabscesses occurred in the hematopoietic tissues. In a fish that was moribund at 4 days after inoculation in the high dose group, thrombi were observed in the vein of the kidney (Fig. 4D).

In the liver, bacterial invasion were less severe than those observed in the spleen and kidney. Hepatic lesions with bacterial invasion were often observed in infected fish that were moribund at 5-10 days after inoculation in the high and low dose groups. There were some small necrotic foci with bacteria in the hepatic parenchyma. Necrotic cells showed karyopyknosis, hyperchromatosis of the nuclear membrane and coagulation. In advanced cases, microabscesses occurred in the hepatic parenchyma. The microabscesses in liver contained numerous bacteria associated with necrotized neutrophils and hepatocytes (Fig. $4 \mathrm{E})$. Some of the bacteria were engulfed in the neutrophils in the abscess. In all of the infected fish, hepatocytes showed either atrophy or cloudy swelling with enlarged nuclei. The sinusoids were dilated. No bacterial invasion was observed in these lesions.

In some fish, slight necrosis and inflammatory cellular infiltration with bacterial invasion were observed in the myocardium (high dose group: 6 of 16 tested fish, low dose group: 2 of 15 tested fish). Slight bacterial invasions were also observed in the gill, alimentary tracts, abdominal adipose tissue and pancreas, whereas no distinct lesions were observed in these organs. No pathological features including bacterial invasions were observed in the brain and trunk musculature. The survivors of challenge groups did not show any lesions which were found in moribund and dead fish.

In the IPI challenge groups, lesions of the spleen, 

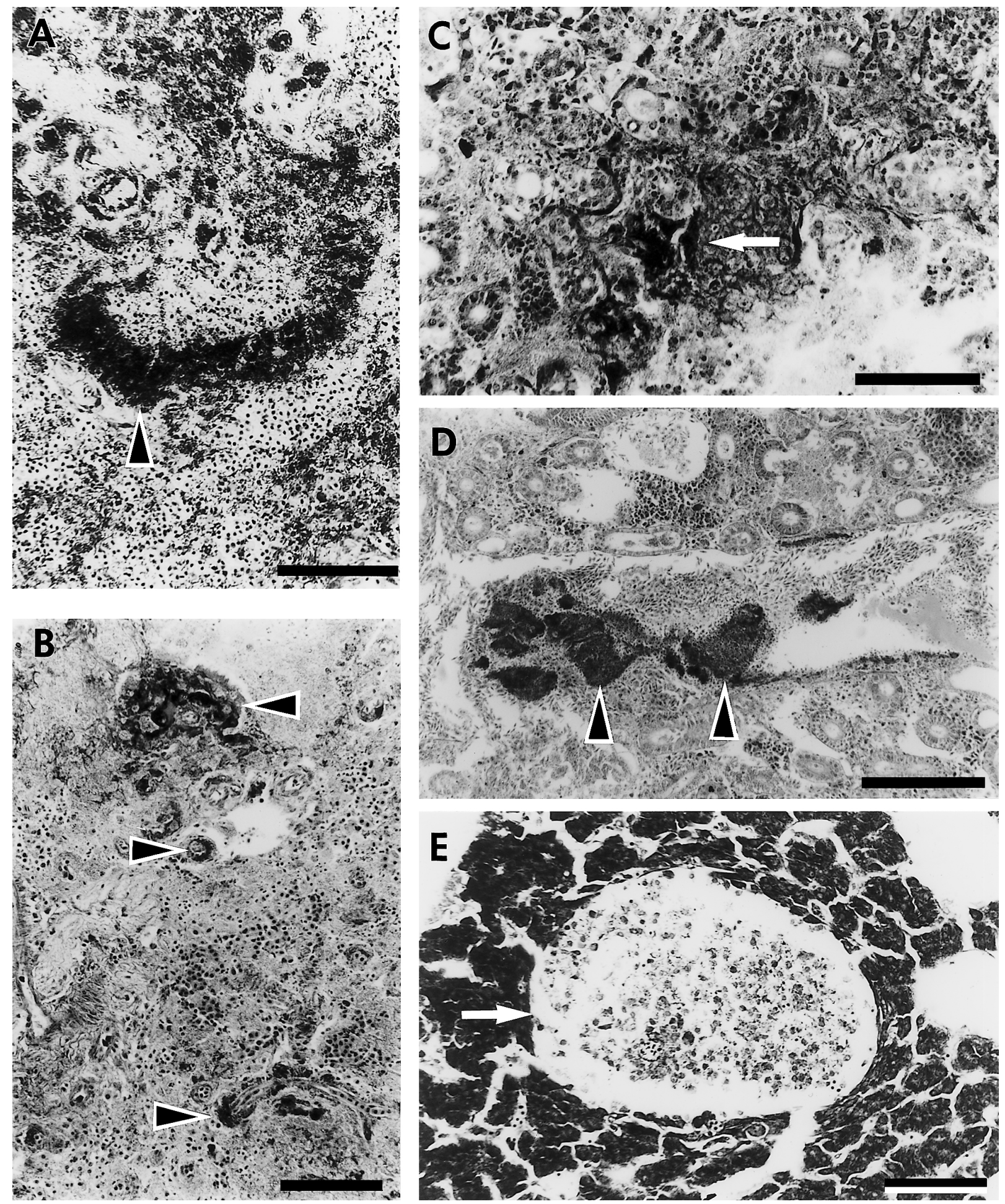

Fig. 4. Histopathological features of ayu challenged by an immersion method. All scale bars indicate $50 \mu \mathrm{m}$. (A) The spleen of an infected fish at 4 days after inoculation with $2.1 \times 10^{7} \mathrm{CFU} / \mathrm{mL}$. The splenic tissues with bacterial invasions (arrowhead) display extensive necrosis, and hemorrhage and edema. Giemsa stain. (B) The spleen of an infected fish at 4 days after inoculation with $2.1 \times 10^{7} \mathrm{CFU} / \mathrm{mL}$. The sheathed arteries and blood vessels of the splenic pulps display necrosis accompanied by fibrinoid degeneration (arrowheads). Azan stain. (C) The kidney of an infected fish at 5 days after inoculation with $2.1 \times 10^{7} \mathrm{CFU} / \mathrm{mL}$. The hematopoietic tissue with bacterial invasions displays extensive necrosis accompanied by fibrin deposition (arrow). Azan stain. (D)The kidney of an infected fish at 4 days after inoculation with $2.1 \times 10^{7} \mathrm{CFU} / \mathrm{mL}$. Thrombi (arrowheads) are visible in the vein and the along vascular wall. The thrombi consist of fibrin. Hematopoietic tissue displays extensive necrosis and the sinusoids are dilated. Azan. (E) The liver of an infected fish at 10 days after inoculation with $2.1 \times 10^{7} \mathrm{CFU} / \mathrm{mL}$. A microabscess (arrow) containing many bacteria, neutrophils and necrotic cells. The hepatocytes around the abscesses were atrophied or deformed and the sinusoids were dilated. Giemsa. 


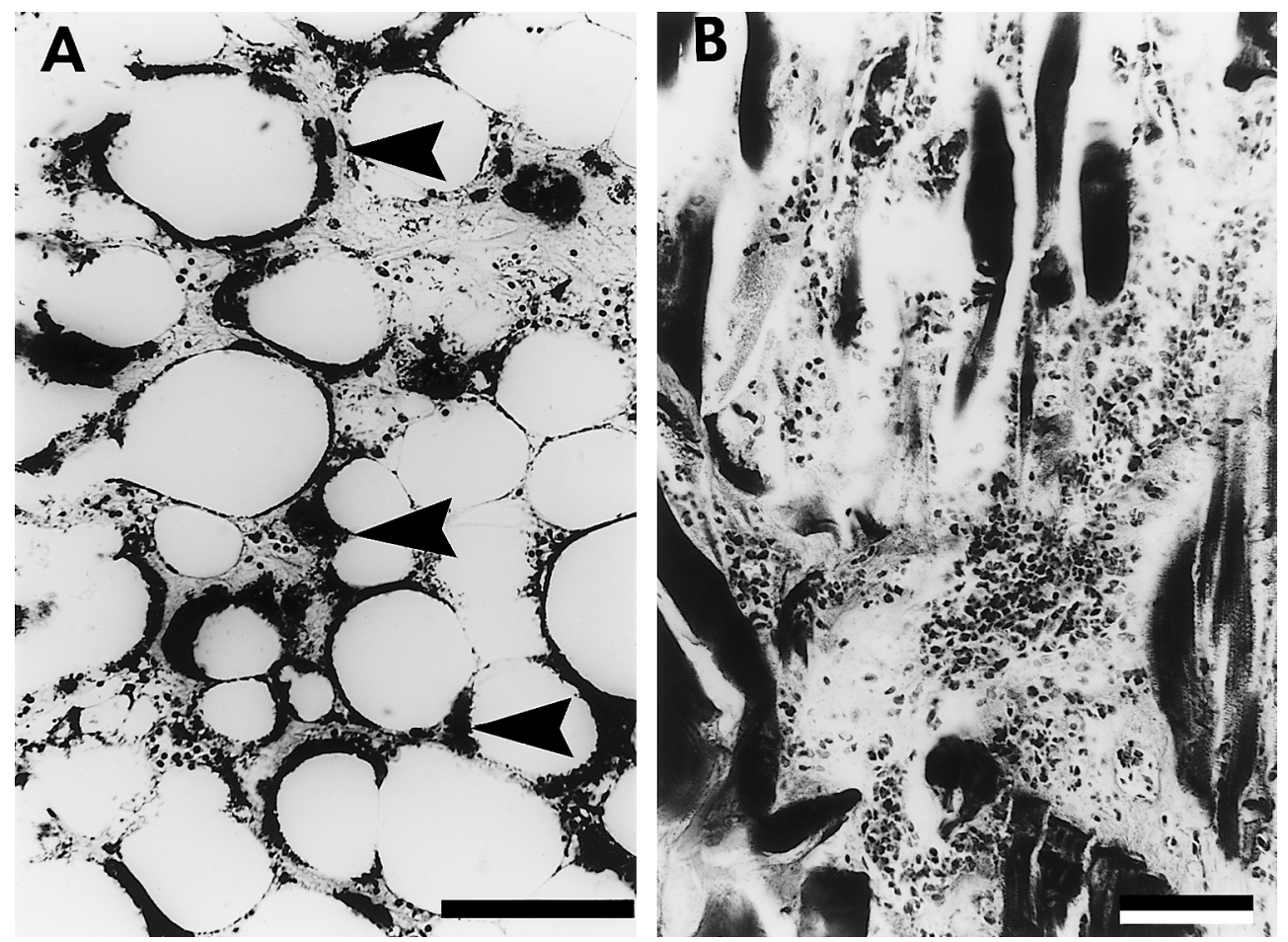

Fig. 5. Histopathological features of ayu challenged by injection methods challenge. All scale bars indicate $50 \mu \mathrm{m}$. (A) The abdominal adipose tissue of an infected fish at 5 days after intraperitoneal injection with $6.5 \times 10^{4} \mathrm{CFU} /$ fish. The abdominal adipose tissues with bacterial invasions (arrowheads) display necrosis and hemorrhage accompanied by inflammatory cellular infiltration and fibrin deposition. Giemsa. (B) The musculature of an infected fish at 2 days after intramuscular injection with $2.3 \times 10^{7} \mathrm{CFU} / \mathrm{fish}$. The musculature at the injection site displays necrosis accompanied by hemorrhage and inflammatory cellular infiltration. Affected muscle fibers showed atrophy, fragmentation, splitting and hyalinisation. Azan.

kidney and liver were similar to those observed in the IM challenge groups. The hepatic lesions with bacterial invasion were often observed in the infected fish of the low dose group. No abscess formation was observed in the spleen, kidney and liver. In the infected fish of the low dose group, the bacterial invasions were usually present in the abdominal adipose tissues and pancreas. The abdominal adipose tissues were necrotized and hemorrhaged (Fig. 5A). Necrotic lesions were accompanied by inflammatory cellular infiltration and fibrin deposition. Some of the acinar cells of the pancreas showed necrosis.

In some fish, slight necrosis with bacterial invasions was observed in the heart (high dose group: 3 of 16 tested fish, low dose group: 1 of 14 tested fish), gill (high dose group: 3 of 16 tested fish) and alimentary tracts (high dose group: 1 of 16 tested fish, low dose group: 2 of 14 tested fish). No lesions and bacterial invasions were observed in the brain and trunk musculature. No obvious histopathological changes were observed in one survivor of the low dose group.

In the IMI challenge groups, lesions of the spleen were similar to those in the IM and IPI challenge groups. Lesions of the trunk kidney were slighter than those observed in the other challenge groups, and small focal necrosis with bacterial invasion occurred frequently. Focal necroses of hepatic parenchyma were mainly observed in the infected fish of the low dose group, and were similar to those shown in the IM and IPI challenge groups. No abscess formation was observed in the spleen, trunk kidney and liver. All of the infected fish in the high and low dose groups had distinct lesions in the trunk musculature at the injection site. The musculature at the injection site was necrotized and accompanied by hemorrhage and inflammatory cellular infiltration (Fig. 5B). Affected muscle fibers showed atrophy, fragmentation, splitting and hyalinisation. In the heart, slight necrotic lesions and inflammatory cellular infiltration with bacterial invasion were mainly observed in the myocardium of infected fish of the high dose group.

In some fish, slight bacterial invasion was observed in the gills (high dose group: 2 of 9 tested fish, low dose group: 3 of 10 tested fish). No pathological features including bacterial invasions were observed in the brain, alimentary tracts, abdominal adipose tissue and pancreas.

Bacterial invasions and obvious histopathological changes were not observed in the control fish in the IM, $\mathrm{IPI}$ and IMI challenge groups. 


\section{Discussion}

In the present study, the cumulative mortalities of IM, IPI and IMI experimental infection reached around 90 to $100 \%$. These results were similar to the findings obtained in previous studies (Wakabayashi et al., 1996; Sukenda and Wakabayashi, 2000; Park and Nakai, 2003).

This is the first study to describe the histopathological features of $\mathrm{BHA}$ in experimentally infected fish. Histopathological examinations revealed that the most prominent pathological changes occurred in the spleen and trunk kidney. Necrotic lesions accompanied by fibrin deposition, edema and hemorrhage were observed in the splenic tissues and hematopoietic tissue of the trunk kidney with bacterial invasions. The histopathological changes of the spleen and trunk kidney were observed in all of the experimentally infected fish, and were the similar to those observed in the naturally diseased fish (Kobayashi et al., 2004). The results indicate that the lesions of the spleen and trunk kidney are the primary pathological change.

Hepatic lesions with bacterial invasion were often observed in the IM challenge groups, and in the low dose IPI and IMI challenge groups. Disease signs tended to appear sooner in the IPI and IMI groups than in the IM groups, possibly because the inocula were directly injected into the body in the former groups. Many of the fish that became moribund or died early had no hepatic lesions with bacterial invasion. This suggests that the lesions of the liver occur after the occurrence of lesions in the spleen and kidney.

The most prominent features in fish with ascites were severe fibrinous inflammation and necrotic lesions in the spleen and trunk kidney, which correspond to those in naturally BHA infected ayu (Kobayashi et al., 2004). Fish disease cases characterized by ascites have been reported in juvenile yellowtail Seriola quinqueradiata with yellowtail ascites virus (YTAV) infection (Sorimachi and Hara, 1985), and in Japanese eel Anguilla japonica (Funahashi et al., 1973). In yellowtail, the causative factor of ascites was found to be circulatory disorders due to hepatic lesions in YTAV-infection lesions (Miyazaki, 1985; Fujimaki et al., 1986). In Japanese eel, the causative factor was renal insufficiency with severe degeneration in glomeruli and Bowman's capsules (Funahashi et al., 1973). On the other hand, most of the fish examined in this study did not possess distinct lesions in the liver and renal parenchyma, while fibrinous inflammation was frequently observed in the necrotizing spleen and trunk kidney. Thrombus formations were also observed in the necrotizing trunk kidney. The fibrinous inflammation and thrombus formations in the infected fish might indicate the presence of some circulatory disorders including congestion resulted from necrotic lesions in the spleen and trunk kidney. The ascites in the present cases may have been caused by a circulatory disorder resulting from the splenic and renal lesions.

In most of the fish examined, congestion appeared to be present in the livers, in association with atrophy and/or cloudy swelling of the hepatocytes and dilation of the sinusoids, although significant bacterial invasions were not observed in the hepatic lesions. These features suggest that the liver congestion might also be due to a circulatory disorder than a direct effect of bacterial infection. Therefore, the degeneration found in the hepatocytes was mainly caused by anoxic conditions arising from the circulatory disorder. These findings suggest that the circulatory disorders had an important role in pathogenesis of the disease in fish.

In ayu experimentally infected with $P$. plecoglossicida, the spleen and blood were found to have the highest amounts of $P$. plecoglossicida DNA among the organs assayed, which suggests that $P$. plecoglossicida was able to cause a septicemic disease (Sukenda and Wakabayashi, 2000). In the present study, infected lesions or bacterial invasions were observed in the spleen, trunk kidney and liver, but also in the other organs (such as gill, heart and abdominal adipose tissue) in the later moribund or dead fish. These results suggest that $P$. plecoglossicida primarily multiply in the spleen and trunk kidney. Then, the bacteria invade the liver and the other organs except the brain through the circulatory system. Our results are consistent with the suggestion of Sukenda and Wakabayashi (2000) that $\mathrm{BHA}$ is a septicaemia.

\section{Acknowledgement}

We gratefully acknowledge Dr. H. Wakabayashi for kindly providing antiserum against $P$. plecoglossicida FPC941.

\section{References}

Fujimaki, Y., K. Hattori, K. Hatai and S. S. Kubota (1986): A light and electron microscopic study on yellowtail fingerlings with ascites. Fish Pathol., 21, 105-111. (In Japanese with English summary)

Funahashi, N., T. Miyazaki and S. S. Kubota (1973): Histopathological studies on ascites in cultured eel. Fish Pathol., 8, 68-77. (In Japanese)

Kobayashi, T., Y. Ishitaka, M. Imai and Y. Kawaguchi (2004): Histopathological studies of bacterial haemorrhagic ascites of ayu, Plecoglossus altivelis (Temminck and Schlegel). J. Fish Dis., 27, 451-457.

Miyazaki, T (1985): A histopathological study on serious cases with viral ascites of yellowtail fingerling occurred in Mie Prefecture. Fish Pathol., 21, 123-127. (In Japanese with English summary)

Ninomiya, K. and M. Yamamoto (2001): Efficacy of oiladjuvanted vaccines for bacterial hemorrhagic ascites in ayu Plecoglossus altivelis. Fish Pathol., 36, 183-185. (In Japanese with English summary) 
Nishimori, E., K. Kita-Tsukamoto and H. Wakabayashi (2000): Pseudomonas plecoglossicida sp. nov., the causative agent of bacterial hemorrhagic ascites of ayu, Plecoglossus altivelis. Int. J. Syst. Evol. Microbiol., 50, 83-89.

Park, S. C. and T. Nakai (2003): Bacteriophage control of Pseudomonas plecoglossicida infection in ayu Plecoglossus altivelis. Dis. Aquat. Org., 53, 30-33.

Sorimachi, M. and T. Hara (1985): Characteristics and pathogenicity of a virus isolated from yellowtail fingerlings showing ascites. Fish Pathol., 19, 231-238. (In Japanese with English summary)
Sukenda and H. Wakabayashi (1999): Immersion immunization of ayu (Plecoglossus altivelis) with Pseudomonas plecoglossicida bacterin. Fish Pathol., 34, 163-164.

Sukenda and H. Wakabayashi (2000): Tissue distribution of Pseudomonas plecoglossicida in experimentally infected ayu Plecoglossus altivelis studied by real-time quantitative PCR. Fish Pathol., 35, 223-228.

Wakabayashi, H., K. Sawada, K. Ninomiya and E. Nishimori (1996): Bacterial hemorrhagic ascites of ayu caused by Pseudomonas sp. Fish Pathol., 31, 239-240. (In Japanese with English summary) 